From Making Futures by Pelle Ehn, Elisabet M. Nilsson, and Richard Topgaard (eds.) - MIT Press, 2014. CC:BY-NC.

http://mitpress.mit.edu/books/making-futures

\title{
III Creative Class Struggles
}





\title{
9 Creative Class Struggles
}

\author{
Erling Björgvinsson and Pernilla Severson
}

The emerging of the labels creative industries and creative class is a policy-driven and powerful story of future-making that plays a big part as both the stage and the locality of the stories in this part of the book. The chapters in this part discuss creative workers, sometimes determined to belong to the creative class working in the creative industries. Specifically, they deal with designers, artists, prosumers, and researchers who together explore new ways of producing and engaging in cultural productions. Stories on creative industries, as future-making industries, are as multitudinous and diverse as they are embossed with ideology. Oakley (2009) argues that there is a relationship between innovation and creative industries, where innovation has taken over the role of creative industries as a policy discourse. Garnham $(2005,15)$ states that creative industries have always been about innovation, in which processes of cultural production unjustifiably are linked to economic development and ownership:

This sustains the unjustified claim of the cultural sector as a key economic growth sector within the global economy and creates a coalition of disparate interests around the extension of intellectual property rights.

Stories on the creative industries go back to Theodor Adorno and Max Horkheimer's Marxist writings on the culture industry (2002). Their work was the starting point of a long historical struggle to articulate who should pay for the making of culture and what role it should play in society - a struggle that is still fervent, and that involves quite different perspectives on how the cultural industries should be financed and how cultural products should be made available and who should be given the opportunity to shape the future of the industry by having access to knowledgeable individuals and to funding for research and development.

In many cases, cultural productions, and the same goes for research and development within the cultural industries, come about through collaborations that cut across the public and the private, the state and the market, and state funds and private funding. Given that cultural productions cut across public and private spheres, how the balance between individual ownership and common good and the balance between cultural capital and economic capital should look is up for debate. 
The people in the enterprises that figure in these chapters range from people being involved in cultural productions that are purely financed by private capital arguing that cultural enterprises should aim for economic growth, to those that argue for a mix of state and private financing of cultural production, to people that argue for the importance of social, cultural, economic, and ecological sustainability. Sustainable enterprises are not growth oriented, as more employees and higher turnover is not what guides their business. These enterprises do not fit the traditional definition of entrepreneurship and have therefore been overlooked by academic innovation research, innovation policy making, and innovation funding, as Fischer (2010) points out.

Given that cultural industries cut across the private and public, in relation to law, policy making, and funding, the various creative industries-film, music, literature, gaming, design-form numerous complex public spheres in which the political and governing (Barry 2001) are distributed rather than neatly contained within a national government and the official political sphere. And as the innovation discourse perhaps has replaced the creative industry discourse, what voices, alliances, and issues can affect and rearrange these public spheres into future practices is a governing issue, a political issue, and thus a democratic issue. As was stated earlier, different creative industries, creative classes, and enterprises face different challenges, have different expectations, and hold different ideas about the future. Therefore, value frictions pertaining to social, cultural, technical, and economic issues are embedded in democratic innovation. These frictions are articulated in these chapters by stories on actual future-making practices. Our hope is that our insights into opportunities and dilemmas facing these practices will influence the discussion on media development and contribute to a more democratic media development.

The chapters in this part of the book sketch some of the significant features of open innovation and participatory design through public co-productions carried out by researchers and actors operating within creative industries and the cultural sector in Malmö. They also present images, stories, and actions of future-making derived from a set of interviews with managers working in IT, design, and media companies in southern Sweden.

\section{The making of creative industries and the creative class}

In the making of creative industries, history starts with art (Hartley and Cunningham 2001). Here we retell the story of when creative and industries became creative industries, adding Swedish examples of the policy-driven development and taking a more critical approach. We do so to show how cultural production has increasingly become defined primarily as an industry, how it has become entangled in the innovation discourse, and to open up articulations of how these policy-driven discourses, at times, do not match 
the reality facing many individuals and enterprises operating within the creative industries. The creative industries are in fact engaged in a creative class struggle.

Strangely, as Hesmondhalgh and Baker (2011) point out, labor studies on creative production, despite how important the industry is considered to be, are meager. Hesmondhalgh and Baker note that neither the political economy of culture (PEC) perspective nor studies by political economists nor business and management studies nor cultural studies have focused extensively on labor. They define creative labor as a form of business in which the primary aim is to profit from "the activity of symbol-making" (ibid., 9), which consists of division of labor that produces distinctions and hierarchies within the creative labor force. The division of labor can crudely be divided into managers, professionals, and unskilled workers. Hesmondhalgh and Baker, referring to Wright (1997), argue that most cultural workers have high skills and low authority, whereas managers have high authority and high wages. The high wages buy their loyalty to the capitalist class. The managers, in turn, use wages as a loyalty-enhancing mechanism, and as a result only a few workers with sought-after talents get well paid.

The class concept is vital to Florida's arguments on the existence and importance of creative industries. Florida $(2002,8)$ defines the creative class as "a cluster of people who have common interests and tend to think, feel and behave similarly," where the similarities are determined by economic functions. Florida claims that we are entering a new class structure in which new class divisions are created between the creative class, the service class, the working class, and the agricultural class. A central attribute of members of the creative class is that they "add economic value through their creativity, creativity being the ability to create meaningful new forms" (Florida 2002, 68).

The creative class is a constructed concept. Florida argues that the class can be divided into two subgroups: the super-creative core and the creative professionals. "The super-creative core of this new class," he writes, "includes scientists and engineers, university professors, poets and novelists, artists, entertainers, actors, designers, and architects, as well as the 'thought leadership' of modern society: nonfiction writers, editors, cultural figures, think-tank researchers, analysts, and other opinion-makers" (Florida $2002,34)$. The creative professionals, on the other hand, are found in as diverse areas as in management, legal, business, and financial occupations, and among health-care practitioners and people in high-end sales.

These groups' shared ideas and view on the world, what Florida calls their creative ethos, is a synthesis of bohemian values and a Protestant work ethic. According to Florida they are not aware that they belong to a class, and Florida's goal is to raise their class awareness.

Florida has been criticized for operating with a vague definition of class and for downplaying complexity and internal class struggles (Jeppesen 2004). His focus is primarily on how cities need cultural workers rather than on what cultural workers need, 
which is why his work has resonated better with politicians, policy makers, and branding consultants than with cultural workers. The underlying rhetoric of competitiveness also clashes with more commonality-oriented perspectives that argue for the value of all citizens; a perspective that is uneasy with pitting regions, cities, or people against one another.

Since the late 1990s, few terms have been more loaded with future hopes, or have at least been believed to point toward a new future for the Western world in a postindustrial era where manufacturing has for the most part moved to the eastern hemisphere, than the twin terms creative industries and the creative class. The terms have functioned as projections and rhetorical devices affecting government policies and research funding on European, national, regional, and municipal levels. As these terms have dealt with bright visionary futures, almost utopian in character-policy actions that have centered on the possibility of establishing new enterprises, economic growth and the branding of cities to attract hip, well-educated cultural workers- has become a battleground. One city after another has claimed to be uniquely creative. The terms have caused battles over what individuals and what groups are considered creative, and whether individual entrepreneurs or collectives are to be premiered. In the relationship between governmental funding, enterprise business logic, and the self-made cultural workers, the connection between capital and creativity becomes a question of to what degree the creative practices should be industrious?

The term creative industries is tightly linked to the notion of new forms of business. According to Cunningham $(2002,54)$, “'creative industries' ... can claim to capture significant 'new economy' enterprise dynamics that such terms as 'the arts,' 'media' and 'cultural industries' do not." According to Flew $(2002,3)$, the concept of the creative industries grew out of a specific socio-political circumstance and, as is well known, was the construct of policy makers in Great Britain: "The formal origins of the concept of the creative industries can be found in the Blair Labour Government's establishment of a Creative Industries Task Force after its election in Britain in 1997, where the newlycreated Department of Culture, Media and Sport (DCMS) set about mapping current activity in the creative industries, and identify policy measures that could promote their further development."

Closely linked to Blair's neoliberal venture into creative industries was Charles Leadbeater, who advised the British government on the knowledge-driven economy, the Internet, and the relationship between the two. Juxtaposing old and supposedly defunct organizational models found within big companies and universities with the more agile and inventive passionate self-organized Pro-Am consumers who have turned into professional amateur producers was central to Leadbeater and Miller's ways of arguing (Leadbeater and Miller 2004; Leadbeater 2004). Pro-Ams, they argued, are in closer touch with what needs to be developed and are therefore one step ahead of conventional producers. 
Leadbeater and Miller further argued that governments needed to understand that creativity and innovation is not to be found in special people with special skills that meet in special places. Policy makers are mistaken when they think that they need more R\&D parks since today large organizations that gather specialized skills are not needed in order to be inventive. Instead, policy makers needed to acknowledge the power of Pro-Ams and their way of organizing without organizations, which can intensify with the help of the Internet. Although Leadbeater acknowledges that innovation is cumulative and collaborative, something that some researchers of innovation-e.g., Bijker (1995)—would agree with, he still argues that big disruptions are possible and that they come from users and only rarely, if at all, from large organizations and mainstream markets.

Increasingly, the driving force of the economy, according to Leadbeater, is creativity, ingenuity, and imagination rather than raw materials, land, labor, and machinery, which were the central assets of the industrial age. Today, he claims, an increasing number of people make a living from their ideas and know-how or what he calls making a living from thin air (Leadbeater 1999). To foster innovative and inclusive thin-air creative practices, what needs to be acknowledged and foregrounded is the value of knowledge capital and social capital rather than such inhumane aspects as efficiency and increasing global corporate profit. This refocusing of values, in turn, demands organizational reorientation. A new breed of competitive creative communities are needed if one wants to survive in the global economy that are based on networks and spread-out ownership.

Although Leadbeater acknowledges that the thin-air economy is due to long-standing accumulation of knowledge within science and education, his juxtaposition of old and new ways of organizing was unfortunate. Other research shows that it doesn't hold true that small and agile necessarily means that one is more innovative. Big media corporations can foster innovative changes and productions as Hesmondhalgh and Baker (2011) point out. Size doesn't necessarily matter. Leadbeater also disregards Mode 2 (Gibbons et al. 1994; Stålbröst 2008) innovation initiatives, which have acknowledged the need to create bridges between research and societal practices. And, as McRobbie (2009) has argued, Leadbeater and others, with their neoliberal views, have idealized the creative entrepreneur as a way toward economic growth. This they have done at a time when cultural practices are increasingly expected to become entrepreneurial and take care of themselves leading to increased cultural individualization, competition, instability, and mobility; this at a time when societal structures supporting young up-and-coming creative talents have considerably diminished. It could even be argued that his arguments, although wanting to create a more modern and humane world of competitive communities, has contributed to individualization, instability, and mobility as policy makers and politicians have followed some of his advice. 


\section{Creative industries, democracy, and innovation}

A discussion on democracy and innovation is to a large degree absent in research, in policy, and in the practices of creative industries. The exception is Eric von Hippel's book Democratizing Innovation (2005). Just as Leadbeater does, von Hippel acknowledges that the modes of production have to some degree changed, which has opened up for increased user-driven innovation. Innovation has become democratized, he claims, because information and the means of production-cheaper and more easily handled tools-have become more readily available leading to that more individuals can innovate. Innovation is thus defined as making discrete objects or products. Democracy is equated and delimited to having increased access to information and tools to make more products. And although von Hippel acknowledges users that are active creators, this rings true only to a small elite of lead users or domain experts who benefit from increased access to information and means of production-lead users, individuals who are ahead of the general market. To von Hippel democratization of innovation is therefore some sort of competitive elite market democracy. More recently this perspective has been problematized as focusing too much on lead users, ignoring the democratic responsibility of attending to the multitude of groups and perspectives that make up a democratic society (Björgvinsson, Ehn, and Hillgren 2010, 2012), and ignoring the responsibility of a democracy to attend to and take into account those marginalized by the majority rule. This alternative perspective argues that a more central issue pertaining to democratizing innovation is what groups are given access to participating in future-making, rather than solely the access to information and advanced means of production. In doing so, this perspective has built upon Mouffe's (1996) notion of agonistic controversies. It has aimed, through action-oriented research, at creating arenas in which different actors in society collaboratively explore future democratic media practices, rather than focusing on how products or services can be ahead of the market.

What groups are included and can get governmental funding is of particular relevance because research funding is an important innovation infrastructure device. EU's structural funds, which have partly financed the work discussed in this book, is an example of multilevel organizing of democracy where public and private actors collaborate horizontally across local, regional, national, and European levels to promote their interests (Erlingsson 1999). This is an organizational form that is not particularly transparent, open, or public, and which is heavily driven by lobbyism. It is an organizational form that some argue is a new form for democratic decision making, while others argue that semi-transparent lobbyism is anti-democratic. These regional funding strategies have also played some part in the spatial politics and the location and invigoration of creative hot spots. 


\section{The making of a creative class in Region Skåne and Malmö}

Richard Florida's notion of the creative class has widely influenced politicians and city planners. His ideas have directly influenced political initiatives in southern Sweden, particularly in Malmö, for the last decade. Along similar lines as Leadbeater, Florida argued that we were witnessing substantial changes of values and ways of organizing. Cultural workers value rewarding work in which they can express themselves and their ideas and can learn and grow. They are driven by intrinsic motivation and peer recognition. They also value independent work that they can control and self-manage. These cultural workers do not look for safe jobs in which they can climb the corporate ladder; they look for tolerance, talent, technology, openness, and diversity. If cities are to become successful, they need to provide the three T's as the creative class, which is rising to power, generates economic growth. These cultural workers are, however, not interested in local traditional communities, but rather in communities that generate economic prosperity. Florida's main influence was making the connection between creativity, economic growth, and geographic concern, which to some degree fueled the spatial politics of growth. Current and future prosperity became a spatial competition, Malmö and other cities were working hard to brand themselves as creative and even measuring their talent, technology, and tolerance. According to one report (Mellander et al. 2010), 11 percent of Malmö's citizens were xenophobic, 14 percent were homophobic, 16 percent were unwilling to live next door to Muslims, and over 41 percent were unwilling to live next door to Romanis. Contrary to official rhetoric and frequent self-proclamations of tolerance, openness, and willingness to experiment, some cultural workers find these figures far from displaying high degree of tolerance, even though the figures are low when compared internationally.

Central to the revitalization of Malmö into a creative and knowledge-driven city, after some dormant years due to the shutdown of large industries, were large urban development projects and the establishment of Malmö University and Media Evolution. The revitalization strategy led to massive demographic changes. During the same time, Malmö also had substantial immigration, which is seldom acknowledged as having contributed to the revitalization.

The cluster formation Media Evolution creates mini-arenas for the creative sector and the creative industries. It has been a central organism of Malmö's "creative ecosystem," as defined by Florida (2002), according to whom a creative ecosystem "can include arts and culture, nightlife, the music scene, restaurants, artists and designers, innovators, entrepreneurs, affordable spaces, lively neighborhoods, spirituality, education, density, public spaces and third places" (ibid., 381). Media Evolution, framed as a cluster organization, has a clearly defined location, namely Media Evolution City, located in the Western Harbor district of Malmö. Although Media Evolution is in many 
ways an inclusive and open organization, it, like any organization, favors certain perspectives and actors. As was pointed out at Media Evolution's 2009 Annual General Members Meeting, none of the members of the steering board were from small media companies or non-governmental organizations. Members from such companies and organizations also felt that the membership rates, set according to number of employees, were too high and favored large enterprises. In the words of Florida $(2002,8)$, Media Evolution is "a cluster of people who have common interests and tend to think, feel and behave similarly", the similarities being determined mainly by economics.

Malmö University, established in 1998, was also central to the spatial politics of growth in Malmö. The university has been engaged in developing research and innovation strategies for how the private and public sectors and academia can conduct research and development on new media. Central to the research on media and design was the establishment of Medea Collaborative Media Initiative, which focuses on collaborative media and collaborative design research as it engages with society.

The design cases discussed in this part of the book were conducted through Malmö Living Lab the Stage. The purpose of Living Lab the Stage was to try out co-production models through the formation of various constellations of researchers and university students, cultural producers, and IT and media companies. These constellations have explored new forms of practices, expressions, services, and products through long-term engagements and iterative small-scale experiments in real-world contexts. This, in turn, has meant that the activities of the lab have been carried out in various locations in the city, but at times also connected to other places; each constellation and issue that has been researched generated its specific geography.

Over the years, the lab has worked with an arts and performance center and a media work center for visual artists and small publishers of literature and cultural magazines and some of their authors. It has also worked with small independent record companies and some of their artists, a hip-hop youth organization, and small up-and-coming independents filmmakers as well as with more established public and private media companies, newly established interaction design and industrial design bureaus, and more traditional IT companies.

Through the lab, cultural producers, artists, designers, media producers, and IT developers have negotiated as they envisioned the future together. One aspect of the work has been to create constructive and productive bridges for all the heterogeneous actors involved in addressing and envisioning the future, and to try to do so in a socially accountable way. The work carried out in the lab has given the researchers insights into how individuals and large and small companies organize their work and into how they relate to and act in relation to cultural capital, commerce, openness, coproduction, democracy, and innovation.

The lab has found it important to open up participation to small content producersnot out of a belief that they are more innovative or agile, but rather on the basis of the 
democratic ideals of participatory design. This has reconfigured how interaction design research and innovation are conducted, as it takes as its starting point the concerns currently facing these actors when challenging current infrastructures from the margins or, in the words of Suchman (2008, no paging), "disrupt[ing] particular arrangements," rather than imagining how the future could be ten years down the road.

The cultural sector, now often called the creative industries or the creative class, consists of various classes and public spheres that have distinct value systems and preconditions for producing and making a living. Physical, social, human, monetary, and creative capital are related to each other and are managed in different ways depending on what creative class the actors belong to. Bringing small and marginal enterprises and non-governmental organizations into the same story and future-making activities as more central powerful enterprises can at times lead to navigational difficulties, conflicts, and capsized collaborations. Two of the questions it raises are "Is collaboration between disparate creative classes desirable?" and "Do big issues need big companies?" At times, it is of value to collaborate with like-minded people. As one of the chapters in this part shows, infrastructures cannot change without powerful networks of people sharing the same values. Yet we can also see that aligning to different networks is important for different creative classes and enterprises within the creative industries. Collaborating and building bridges across organizational and professional borders is seldom easy. Problems quickly arise, some of them having to do with culture and capital.

\section{Prominent themes}

In this part of the book the creative class is analyzed through a set of collaborative design cases and through an interview study of creative industries managers. Internal class struggles and the complexity of the field of creative work are described and analyzed. The creative class is indeed a heterogeneous group with internal conflicts. Workers control the means of production because it is mental labor that is produced (Florida 2002), but the creative class still sells its labor in order to make a living. The shift from the feudal to the capitalist way of production focuses internal struggles on commodification rather than emancipation. Problems are discussed to clarify boundaries and what is taken for granted. There are dominating classes defending their position and justifying economic ideals of growth as the starting point for production. The agents see, judge, and act very differently depending on whether they are dominating or dominated. Depending on context and capital, there is a struggle between the super-creative core and the creative professionals. The creative professionals can be the hegemonic power.

The actors that we have interviewed and co-produced together with have in the interviews and during the co-production reasoned about the relationship between culture and capital and how they would like to and can position themselves. To gain 
cultural capital, one must disavow economic capital. Symbol production and symbol distinction, central aspects of cultural production, are always at play, though in different guises; as a product or event that is unique, as altruistic and autonomous creation with high level of integrity and quality, or as promoting craftsmanship and communality, or as embracing popularity and commerce. Creative workers, operating within the realm of culture and creative industries, inevitably face the challenge of where to position themselves on the industry-creative autonomy spectrum.

The tension between cultural commons and private property is particularly important. The relationship between private ownership of content or products and the common good is in no way settled, and it highlights democratic issues relating to cultural production. The actors in the chapters on co-production articulate tensions and challenge presuppositions about what is part of the cultural commons and what is private property. The interviewed managers' standard view is that cultural products and content is private property, where cultural commons is understood as being separated from the production being made and taken care of somewhere else. Democratic issues of cultural production are, if not dichotomized, marginalized or considered a non-issue by the creative industry class, and thus left to be taken care of by the cultural producers.

Another tension concerns what forms of collaborations are considered valuable and doable. The stories from design cases and interviews relating to open or closed innovation show that some people do not have the time to engage in collaborative research projects although they would want to engage in these kind of projects. Not only is open innovation time consuming; it also demands specific competences, which makes it difficult for some actors to become engaged in such innovation. They see participation in slow processes, which networked collaborations demand, as a form of luxury. Friction occurs when an actor can see the value of collaborating but is unable to engage in it. Friction also occurs in collaborative and networked research and development, but for the most part the various actors can tolerate it, as they gain from the collaboration even when they have to compromise some of their values.

Linked to the organization of work, and specifically to the matter of autonomy, is the issue of how to balance communality and individual autonomy. In critical theory, autonomy is described as a desirable political goal (Adorno 2004). Marshall (1996) points out how Adorno's notion of autonomy refers to liberty, and Marcuse (2001) how liberty is a mode of existence where true autonomy exists; an autonomy that allows people to practice altered consciousness, which allows them to break away from prevailing societal perceptions. McRobbie (2003) argues that the logic within creative industries is that the more autonomous you are, the more creative you can be-but that autonomy also comes with a price. This resonates with Hesmondhalgh and Baker's (2011) discussion of autonomy as a feature of good work. They argue that cultural workers lack managerial power and that friction between creative autonomy and commercial imperatives is a threat to creative autonomy. According to Habermas (1992), 
deliberative communication builds on political autonomy, which can be realized only in a joint enterprise in an intersubjective shared practice, not by a person pursuing his or her private interests. Habermas (ibid.) is therefore looking for forms of living together in which autonomy and dependency can truly enter into a non-antagonistic relation. In our studies this is articulated as the individual being able to be creatively autonomous and also having to withdraw from the structures of commercial imperatives. An enterprise can never defect from commercial imperatives, but an enterprise can commit to communality, supporting creative autonomy not only as an egoistic aspect but also as an opportunity to fulfill obligations to other people and the society at large. If we look into the professional lives of the actors in the interviews and in the co-producing practices, we can see that the relationship between autonomy and dependency is still antagonistic, and that the ability to control one's own production is sometimes decreased by collaboration and co-production.

We conclude this introductory chapter on class struggles within the creative industries by making prominent what it adds to earlier knowledge production: the locating of future-making. In the tense relationship of culture and capital, a prism of futuremaking reveals friction between industry and cultural production as how to approach future-making and newness, what we call disengaged futures or engaged nows. Cultural producers and the more industrious IT companies approach the future quite differently, but also show some similarities. One obvious similarity is that they both engage in practices of producing that which is new or at least considered new rather than mere imitation. However, how to approach the future differs considerably whether you belong to an IT and design company engaged in research and development or you are a cultural producer in relation to how far into the future the future tense stretches. Some international IT and design firms, often large ones, can engage in developing future scenarios and concepts, and at times prototypes that explore products and services that may be launched five to ten years later. Other IT and design companies do not have the opportunity to do $\mathrm{R} \& \mathrm{D}$ for potential products that may be launched years later. The logic of innovation they operate under is that they innovate and develop when their products or services need to be updated or have become obsolete. They are thus involuntarily entrepreneurs that innovate when trapped. Yet, a common approach to research and development within companies is to approach the future as disentangled from the now. Cultural producers, on the other hand, have little opportunity to engage in future scenarios or beta productions, as they operate under the logic of one production's leading to the next. They do this through rehearsing, which is their equivalent to prototyping and beta production. Nevertheless, the production that they are engaged in should aim at some form of distinction so that it can be recognized as new when presented. There are a few funding bodies that are geared toward cultural development, but such projects cannot simply produce what if scenarios or prototypes; they need to deliver and spread insights gained from the development of cultural practices 
or new forms of expression. As such, they are still focused on sharp productions rather than beta productions or prototypes. In some instances, getting these worlds to meet is challenging because they have considerably different approaches to the future and because their perspective and their modes of production are tremendously different when it comes to future-making. In addition, research conducted at a university in the intersection between media studies and interaction design has traditionally been closer aligned to IT and design firms that engage in research on what can potentially become realized five to ten years down the road. For the research conducted within the Living Lab the Stage, it has demanded considerable reorientation toward sharp productions since it has taken the needs of small cultural producers as its starting point. This reorientation has meant dealing with newness, even more insistently than before, through what Suchman (2008) calls local preoccupations where newness is produced through translation work in a given time and place, rather than as a universal quality produced through practices claiming to be operating at an empty frontier and disconnected from contextual entanglements of power, which often is the case with R\&D conducted in research centers and larger organization.

The notion of innovation, in the form of a policy discourse, has had strong impact on creative labor. It has intensified the notion of industriousness in the term creative industries. In some quarters it is still viewed as a happy marriage with a bright future-for example, in the 2014 Creative Europe program run by the European Union, innovation is given high prominence. More and more, creative workers who have experienced the intensification of uncertainty, flexibility, and mobility have been raising their voices and demanding that cultural productions that cut across the public and private spheres need to become more democratic by loading the future with hopes not mainly made up of capital but also culture that slowly changes as it adds a new sediment to previous layers, reaching back and digging into older layers as it wanders into the future in an ongoing act of remediation.

\section{References}

Adorno, Theodor. 2004. Aesthetic Theory. Bloomsbury Academic.

Adorno, Theodor, and Max Horkheimer. 2002. Dialectic of Enlightenment. Stanford University Press.

Barry, Andrew. 2001. Political Machines. Governing a Technological Society. Athlone.

Bijker, Wiebe. 1995. Of Bicycles, Bakelites, and Bulbs: Toward a Theory of Sociotechnical Change. MIT Press.

Björgvinsson, Erling, Pelle Ehn, and Per-Anders Hillgren. 2010. Participatory Design and "Democratizing Innovation." In Proceedings of Eleventh Biennial Participatory Design Conference. 
Björgvinsson, Erling, Pelle Ehn, and Per-Anders Hillgren. 2012. Agonistic Participatory Design: Working with Marginalized Social Movements. CoDesign 8 (2-3): 127-144.

Cunningham, Stuart. 2002. From cultural to creative industries: Theory, industry, and policy implications. Media International Australia Incorporating Culture and Policy: Quarterly Journal of Media Research and Resources: 54-65.

Erlingsson, Gissur Ó. 1999. Ekonomi, demokrati och identitet $i$ ett Europa under omvandling. En analys av ett forskningsområde. Department of Political Science, Lunds Universitet.

Fischer, Josefine. 2010. The Other Entrepreneur: Alternative Approaches to Economics, Culture and How to Do Business. CIRCLE. University of Lund.

Flew, Terry. 2002. Beyond Ad Hocery: Defining Creative Industries. Paper presented at Second International Conference on Cultural Policy Research, Wellington, New Zealand.

Flew, Terry. 2011. Origins of Creative Industries Policy. In The Creative Industries: Culture and Policy. Sage.

Florida, Richard. 2002. The Rise of The Creative Class. Basic Books.

Garnham, Nicholas. 2005. From Cultural to Creative Industries: An Analysis of the Implications of the "Creative Industries" Approach to Arts and Media Policy Making in the United Kingdom. International Journal of Cultural Policy 11 (1): 15-29.

Gibbons, Michael, et al. 1994. The New Production of Knowledge: The Dynamics of Science and Research in Societies. Sage.

Habermas, Jürgen. 1992. Autonomy and Solidarity. Verso.

Hartley, John, and Stuart Cunningham. 2001. Creative Industries: From Blue Poles to Fat Pipes. In The National Humanities and Social Sciences Summit: Position Papers, ed. M. Gillies. Department of Education Science and Training, Canberra.

Hesmondhalgh, David, and Sarah Baker. 2011. Towards a Political Economy of Labour in the Media Industries. In The Handbook of Political Economy of Communications, ed. G. Murdock, H. Sousa, and J. Wasko. Wiley-Blackwell.

Jeppesen, Troels. 2004. The Creative Class Struggles. Kontur 10: 20-26.

Leadbeater, Charles. 1999. Living on Thin Air: The New Economy. Penguin.

Leadbeater, Charles. 2004. Personalisation through Participation. Demos.

Leadbeater, Charles. 2008. Charles Leadbeater: The Rise of the Amateur Professional (http://www .youtube.com/watch?v=W7raJeMpyM0).

Leadbeater, Charles, and Paul Miller. 2004. The Pro-Am Revolution: How Enthusiasts Are Changing Our Economy and Society (http://www.demos.co.uk/publications/proameconomy). 
Marcuse, Herbert. 2001. Towards a Critical Theory of Society: The Collected Papers of Herbert Marcuse, Volume Two, ed. D. Kellner. Routledge.

Marshall, James D. 1996. Michel Foucault: Personal Autonomy and Education. Kluwer.

McRobbie, Angela. 2003. "Everyone Is Creative": Artists as Pioneers of the New Economy? (http:// www.k3000.ch/becreative/texts/text_5.html).

McRobbie, Angela. 2009. Vi är alla kreativa. In Kultur och politik, ed. Y. Gislen et al. Fronesis.

Mellander, Charlotta, et al. 2010. Skånes kreativa kapacitet-Talang, tolerans och den kreativa klassen (http://www.skane.se/upload/Webbplatser/Strukturbild/H\%C3\%B6st\%2010/skanes_kreativa _kapacitet_OK.pdf).

Mouffe, Chantal. 1996. Democracy, Power, and the "Political." In Democracy and Difference, ed. S. Benhabib. Princeton University Press.

Oakley, Kate. 2009. The Disappearing Arts: Creativity and Innovation after the Creative Industries. International Journal of Cultural Policy 15 (4): 403-413.

Stålbröst, A. 2008. Forming Future IT: The Living Lab Way of User Involvement. Doctoral thesis, Luleå University of Technology.

Suchman, Lucy. 2008. Striking Likenesses to Difference. Paper presented at annual meeting of Society for Social Studies of Science, Rotterdam.

Wright, E. O. 1997. Class Counts: Comparative Studies in Class Analysis. Cambridge University Press. 